\title{
Social Support and Linkage to HIV Care Following Routine HIV Testing in a Ugandan Refugee Settlement
}

\author{
Canada Parrish $^{1}$ (1) Erica Nelson ${ }^{2} \cdot$ Zikama Faustin $^{3} \cdot$ Joshua Stern $^{4} \cdot$ Julius Kasozi $^{5} \cdot$ Robin Klabbers $^{1,4}$.

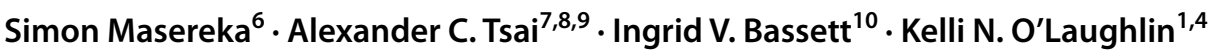

Accepted: 23 January 2022 / Published online: 17 February 2022

(c) The Author(s) 2022

\begin{abstract}
We aimed to identify factors associated with linkage to care for individuals newly diagnosed with HIV in a refugee settlement. This study was conducted from October 2018 through January 2020 in Nakivale Refugee Settlement in Uganda. We conducted a cross-sectional survey among individuals accessing routine HIV testing services. The survey included questions on demographic factors, physical and mental health conditions, social support, and HIV-related stigma. We collected GPS coordinates of the homes of individuals newly diagnosed with HIV. Associations with linkage to care were assessed using bivariate and multivariable analyses. Linkage to care was defined as clinic attendance within 90 days of a positive HIV test, not including the day of testing. Network analysis was used to estimate the travel distance between participants' homes and HIV clinic and to spatially characterize participants living with HIV and their levels of social support. Of 219 participants diagnosed with HIV (out of 5,568 participants screened), 74.4\% linked to HIV care. Those who reported higher social support had higher odds of linking to care compared with those who reported lower social support. On spatial analysis, lower levels of social support were most prevalent in Nakivale Refugee Settlement itself, with more robust social support southeast and west of the study area. Social support is a salient correlate of linkage to care for individuals living in refugee settlements and could be the focus of an intervention for improving uptake of HIV care services.
\end{abstract}

Keywords HIV $\cdot$ Refugee $\cdot$ Uganda $\cdot$ Linkage to care $\cdot$ Social support $\cdot$ Spatial analysis

Canada Parrish

canada05@uw.edu

1 Department of Emergency Medicine, University of Washington, Seattle, WA, USA

2 Department of Emergency Medicine, Brigham and Women's Hospital, Harvard Medical School, Boston, MA, USA

3 Bugema University, Kampala, Uganda

4 Department of Global Health, University of Washington, Seattle, USA

5 United Nations High Commissioner for Refugees, Kampala, Uganda

6 Medical Teams International, Mbarara, Uganda

7 Center for Global Health, Massachusetts General Hospital, Boston, MA, USA

8 Mbarara University of Science and Technology, Mbarara, Uganda

9 Harvard Center for Population and Development Studies, Cambridge, MA, USA

10 Department of Medicine, Massachusetts General Hospital, Boston, MA, USA

\section{Introduction}

Sub-Saharan Africa is home to 25.7 million people living with HIV [1], and over 18.4 million refugees and internally displaced people [2,3]. Refugees suffer hardships including difficulty accessing basic needs, disrupted social networks, and increased susceptibility to mental health problems [4-7]. These adversities increase refugee vulnerability to HIV [4, $6,8]$, and form unique barriers to accessing medical services and engaging in HIV care [5, 8, 9]. In recent years, HIV testing has successfully expanded in many refugee settlements; linkage to HIV care is the critical next step in reaching the UNAIDS 95-95-95 targets [10] in these communities.

Specific factors which facilitate or impede linkage to HIV care for people residing in refugee settlements are not well known [11]. A previous analysis in a refugee settlement in Uganda demonstrated that only $54 \%$ of newly diagnosed adults linked to HIV care within 90 days of diagnosis [12], a significantly lower percentage than non-refugee populations in Africa [13]. Understanding which factors correlate 
with linkage to HIV care for people with HIV in these settings could help tailor interventions to the unique needs of this population.

Our goal was to evaluate the individual, physical, and social determinants associated with linkage to care for people newly diagnosed with HIV in Nakivale Refugee Settlement in southwestern Uganda. We hypothesized that low social support, mental disorders, and greater distance to the nearest clinic would correlate with failure to link to HIV care.

\section{Methods}

\section{Study Setting}

This study was conducted in Nakivale Refugee Settlement in Uganda. This settlement hosts over 130,000 refugees and asylum seekers from 15 countries, predominantly the Democratic Republic of the Congo (DRC) (51\%), Burundi (29\%), Somalia (10\%) and Rwanda (7\%) [14]. Ugandan nationals live in and around Nakivale and access medical services free of charge. A routine HIV testing study at Nakivale Health Center found an HIV prevalence of $4.5 \%$ [15]. Free HIV services, including HIV testing and anti-retroviral therapy (ART), are available for refugees and Ugandan nationals within the settlement.

\section{Study Design}

From October 2018 to January 2020, adults were recruited from the outpatient department waiting area at three of the four health centers in Nakivale. To obtain data on potential correlates of HIV care linkage, we collected surveys from willing clients testing for HIV prior to receipt of their HIV test results. The survey was administered in 4 different languages (Runyankore, Kinyarwanda, Kiswahili, English) and entered into mobile REDCap using electronic tablets. Study data were managed using REDCap electronic data capture tools [16] hosted at the Research Information Science \& Computing. REDCap (Research Electronic Data Capture) is a secure, web-based application designed to support data capture for research studies, providing: (1) an intuitive interface for validated data entry; (2) audit trails for tracking data manipulation and export procedures; (3) automated export procedures for seamless data downloads to common statistical packages; and (4) procedures for importing data from external sources. The survey was approximately $30 \mathrm{~min}$ in length and included questions on demographic factors, health status, mental health conditions, social support and HIV-related stigma. For willing individuals newly diagnosed with HIV, study personnel collected Global Positioning System (GPS) coordinates of their homes.

\section{Variables of Interest}

The outcome of interest was HIV care linkage defined as an HIV clinic visit within 90 days of diagnosis, excluding the day of the initial HIV test. To assess if linkage occurred, data elements were obtained twice monthly from written HIV clinic registers, a method used previously in HIV care cascade research in Nakivale [12].

For self-reported health status, participants were asked, "In general, would you say your health is excellent, very good, good, fair or poor?" Participants were screened for three mental disorders, namely posttraumatic stress disorder (PTSD), anxiety and depression and, as well as for social support and HIV-related stigma. PTSD was assessed using the abbreviated PTSD Checklist; a total score $\geq 14$ was considered indicative of PTSD [17]. The depression module of the Patient Health Questionnaire (PHQ-9) was used to screen for depression [18]; a score of $\geq 10$ was considered a positive screen for depression [19]. Participants were screened for anxiety using the GAD-7, a 7-item general anxiety disorder scale [20]; a score of $\geq 10$ was considered a positive screen for anxiety [21]. These mental health screenings tools have been validated in low-income countries [22], and for use with Ugandan and/or refugee populations [23, 24]. Social support was defined as a binary variable, with higher social support defined by scores $>11$ on a Brief Social Support Scale (BS-6) instrument that assesses emotional and practical dimensions of social support [25]; scores $\leq 11$ indicated lower social support. The BS-6 features items, each scored on a four-point Likert-type scale, that include questions such as, "If you needed it, how often is someone available to help with daily chores if you were sick?". HIV-related stigma was assessed using relevant questions from the Uganda Demographic and Health Survey. [26].

Distance from home to clinic was determined for the subset of individuals newly diagnosed with HIV who consented to geocoding. Road networks from Humanitarian Open Street Maps [27] were used to determine potential travel routes. Network analysis was conducted in ArcPro to estimate the travel distance between the participants' homes and the location of the clinic where they linked to care. To account for homes not on or directly adjacent to the road system, the final travel distance aggregated results from the network analysis and an analysis that calculated the distance between the participants' homes and the nearest connection point with the road system.

\section{Data Analysis}

Chi-square tests, or Fisher exact tests for categories with small frequencies, were used to estimate associations 
between categorical variables, such as sociodemographic characteristics like relationship status and education, and secondary outcomes like HIV status and the primary outcome of linkage to HIV care. T-tests were used for continuous variables such as age and distance to clinic, comparing HIV positive and negative individuals and those who linked and those who did not link to care. We also used logistic regression to calculate unadjusted and adjusted odds ratios (ORs) and 95\% confidence intervals to assess the association between the individual characteristics of interest that were statistically significant in the bivariate analyses and linkage to HIV care.

To anonymize the data and still be able to visualize the distribution of participants with HIV, addresses were geomasked using a random skew algorithm within a maximum/ minimum distance buffer that was informed by the population density at each value. A spatial characterization of individuals who tested HIV positive and screened positive for a lower social support, or lack of social support, was undertaken in ArcMap. Kernel density mapping was conducted using the planar method to visualize levels of social support across the study region represented by densities of 'lack of social support' per square kilometer.

\section{Results}

Of 5568 participants enrolled in the study, most were refugees or asylum seekers $(65 \%)$ with the predominant countries of origin being the Democratic Republic of Congo (24\%), Rwanda (23\%), and Burundi (17\%). Approximately one-third (36\%) of the participants were Ugandan nationals. Among all participants, 219 tested positive for HIV (3.9\% of all participants and $2.2 \%$ of refugees tested). Several statistically significant differences between those who tested positive and negative for HIV were identified (Table 1). Notably, those who tested positive were more likely to be female, more likely to be a Ugandan national, more likely to be divorced/separated/widowed, and less likely to report being in good health. The HIV positive group had a higher proportion of individuals who screened positive for PTSD (50.7\% vs. $43.2 \%, \chi^{2}=4.73 ; p=0.03$ ).

Among the participants newly diagnosed with HIV, $74.4 \%$ linked to care (defined as attend the HIV clinic within 90 days of the day of diagnosis excluding the day of diagnosis). The distance traveled to clinic varied by the health center where participants initially tested for HIV. This distance was not associated with linkage to care in bivariate analyses. For the 145 HIV positive participants for whom we were able to collect GPS data, the median distances traveled ranged from $3.4 \mathrm{~km}$ (2.1 miles) to $10.0 \mathrm{~km}$ (6.2 miles); with maximum distances up to
$54.8 \mathrm{~km}$ (34.2 miles) (Fig. 1). Juru Health Center had a relatively small catchment area with a maximum distance traveled to clinic of $13.2 \mathrm{~km}$ (8.2 miles). Conversely, Nakivale and Kibengo HIV clinics demonstrated large catchment areas with some individuals crossing regional and national borders to obtain care. For participants for whom we had home addresses and linked to care, 23.8\% did not link to care at the clinic nearest their home.

Of the individual factors that were assessed including demographic characteristics, physical and mental health, social support and HIV-related stigma, only social support was associated with linkage to care (Table 1). A larger proportion of participants who linked to care reported higher social support compared with those who did not link to care $(89.4 \%$ vs. $78.2 \%, p=0.03)$. We found that those who reported higher social support had more than two times the odds of linking to care compared with those who reported lower social support $(\mathrm{OR}=2.36,95 \% \mathrm{CI}$ : $1.05-5.34)$. This association remained statistically significant when adjusting for individual characteristics such as sex, age, refugee status, relationship status, and level of education.

Given our findings regarding social support and its association with linkage to care, we conducted a secondary analysis to explore the determinants of social support among HIV positive individuals. In a multivariable logistic regression model restricted to HIV positive individuals $(N=219)$ including individual demographic characteristics of sex, age, refugee status, relationship status, and education level, we found that education was a statistically significant, independent predictor of social support. Those who had some formal education versus no formal schooling had significantly increased odds of reporting higher social support compared to those with no formal schooling $(\mathrm{OR}=4.09,95 \% \mathrm{CI}: 1.52-10.98$ and $\mathrm{OR}=6.14 ; 95 \% \mathrm{CI}$ : $1.12-33.71$ for some primary and beyond primary school, respectively).

The spatial characterization of social support among HIV positive individuals can be seen juxtaposed with the geomasked locations of residence, health care facilities, and the Nakivale settlement boundary in Fig. 1. This kernel density analysis demonstrates significantly low levels of social support in the Nakivale Refugee Settlement itself, and more robust social support among HIV positive participants in the south-east of the study region and in a large swath of the west.

\section{Discussion}

Almost three-quarters of those testing positive for HIV were linked to care within 90 days of diagnosis. We found that most of the demographic, physical and mental health factors of interest were not associated with linkage to care, with 
Table 1 Comparison of HIV testing participants (among all participants) and those who did and did not link to care (among those living with HIV)

\begin{tabular}{|c|c|c|c|c|c|c|c|c|}
\hline $\begin{array}{l}\text { Individual charac- } \\
\text { teristics }\end{array}$ & $\begin{array}{l}\text { Tested } \\
\mathrm{HIV}+N=219\end{array}$ & $\begin{array}{l}\text { Tested HIV- } \\
N=5,349\end{array}$ & Test statistic* & $p$-value & $\begin{array}{l}\text { Linked to care } \\
N=163\end{array}$ & $\begin{array}{l}\text { Not linked to } \\
\text { care } N=56\end{array}$ & Test statistic**** & $p$-value \\
\hline \multicolumn{9}{|l|}{ Demographics } \\
\hline Female, N (\%) & $144(66.1)$ & $2887(54.0)$ & 12.25 & $<0.01$ & $108(66.3)$ & $36(65.5)$ & & 0.91 \\
\hline $\begin{array}{l}\text { Age in years, mean } \\
\text { (SD) }\end{array}$ & $33.0(10.4)$ & $32.2(11.4)$ & 1.10 & 0.27 & $33.2(10.5)$ & $32.5(10.5)$ & -0.40 & 0.69 \\
\hline $\begin{array}{l}\text { Refugee Status, } \\
\quad N(\%)\end{array}$ & & & 92.57 & $<0.01$ & & & & 0.36 \\
\hline Refugee & $79(36.2)$ & $3503(65.8)$ & & & $59(36.2)$ & $20(36.4)$ & & \\
\hline Ugandan National & $132(60.6)$ & $1752(32.9)$ & & & 99 (60.7) & $33(60.0)$ & & \\
\hline Asylum seeker & $6(2.8)$ & $28(0.5)$ & & & $5(3.1)$ & $1(1.8)$ & & \\
\hline $\begin{array}{l}\text { Non-Ugandan } \\
\text { national }\end{array}$ & $1(0.5)$ & $41(0.8)$ & & & $0(0.0)$ & $1(1.8)$ & & \\
\hline $\begin{array}{l}\text { Relationship Status, } \\
\quad N(\%)\end{array}$ & & & 37.12 & $<0.01$ & & & & 0.52 \\
\hline $\begin{array}{l}\text { Married/living } \\
\text { together }\end{array}$ & $109(50.0)$ & $2943(55.1)$ & & & $82(50.3)$ & $27(49.1)$ & & \\
\hline $\begin{array}{l}\text { Divorced/separated/ } \\
\text { widowed }\end{array}$ & $86(39.4)$ & $1231(23.1)$ & & & $66(40.5)$ & $20(36.4)$ & & \\
\hline Single & $23(10.6)$ & $1163(21.8)$ & & & $15(9.2)$ & $8(14.5)$ & & \\
\hline Education, $N(\%)$ & & & 15.04 & $<0.01$ & & & & 0.99 \\
\hline No school & $42(19.3)$ & $1147(21.5)$ & & & $31(19.5)$ & $11(20.0)$ & & \\
\hline Some primary & 119 (54.6) & $2702(50.6)$ & & & $89(54.1)$ & $30(54.5)$ & & \\
\hline Completed primary & $30(13.8)$ & $435(8.1)$ & & & $23(14.5)$ & $7(12.7)$ & & \\
\hline Primary + & $27(12.4)$ & 1061 (19.9) & & & $20(11.9)$ & $7(12.7)$ & & \\
\hline \multicolumn{9}{|l|}{ Health and well-being } \\
\hline $\begin{array}{l}\text { Self-reported health } \\
\text { status, } N(\%)\end{array}$ & & & 50.56 & $<0.01$ & & & & 0.67 \\
\hline Excellent & $4(1.8)$ & $93(1.7)$ & & & $3(1.8)$ & $1(1.8)$ & & \\
\hline Very good & $24(11.0)$ & 988 (18.5) & & & $18(11.0)$ & $6(10.9)$ & & \\
\hline Good & $71(32.6)$ & $2526(47.3)$ & & & $49(30.1)$ & $22(40.0)$ & & \\
\hline Fair & $76(34.9)$ & $1211(22.7)$ & & & $58(35.6)$ & $18(32.7)$ & & \\
\hline Poor & $43(19.7)$ & $517(9.7)$ & & & 35 (21.5) & $8(14.5)$ & & \\
\hline PTSD, $N(\%)$ & $109(50.7)$ & $2289(43.2)$ & 4.73 & 0.03 & $81(50.6)$ & $28(50.9)$ & & 0.97 \\
\hline Depression, $N(\%)$ & $55(25.5)$ & $1288(24.8)$ & 0.05 & 0.82 & $44(27.3)$ & $11(20.0)$ & & 0.28 \\
\hline Anxiety, $N(\%)$ & 49 (22.9) & 1197 (22.9) & 0.01 & 0.99 & $41(25.6)$ & $8(14.8)$ & & 0.10 \\
\hline $\begin{array}{l}\text { High social support } \\
\qquad N(\%)\end{array}$ & 187 (86.6) & 4,611 (88.2) & 0.54 & 0.46 & $144(89.4)$ & $44(78.2)$ & & 0.03 \\
\hline $\begin{array}{l}\text { HIV-related stigma, } \\
\qquad N(\%)\end{array}$ & & & 3.65 & 0.16 & & & & 0.51 \\
\hline None/little & $99(49.0)$ & $2217(42.6)$ & & & 77 (51.0) & $22(43.1)$ & & \\
\hline Moderate & $95(47.0)$ & 2677 (53.9) & & & $69(45.7)$ & $23(51.0)$ & & \\
\hline Extreme & $8(4.0)$ & $176(3.5)$ & & & $5(3.3)$ & $3(5.9)$ & & \\
\hline \multicolumn{9}{|l|}{ Testing location } \\
\hline Health center & & & 7.40 & 0.03 & & & & 0.85 \\
\hline Nakivale & 119 (54.6) & $2675(50.0)$ & & & $90(55.2)$ & $29(52.7)$ & & \\
\hline Juru & 38 (17.4) & $1366(25.5)$ & & & $29(17.8)$ & $9(16.4)$ & & \\
\hline Kibengo & $61(28.0)$ & $1307(24.4)$ & & & $44(27.0)$ & $17(30.9)$ & & \\
\hline $\begin{array}{l}\text { Distance to clinic } \\
(\mathrm{km}) \text {, mean (SD) }\end{array}$ & N/A & N/A & & N/A & $8.0(8.6)$ & $6.7(5.9)$ & -0.72 & 0.47 \\
\hline
\end{tabular}

${ }^{*}$ Chi-square test for categorical variables; two-sample t test for continuous variables

*** Fsher's exact test for categorical variables (test statistic not applicable); two-sample t test for continuous variables 


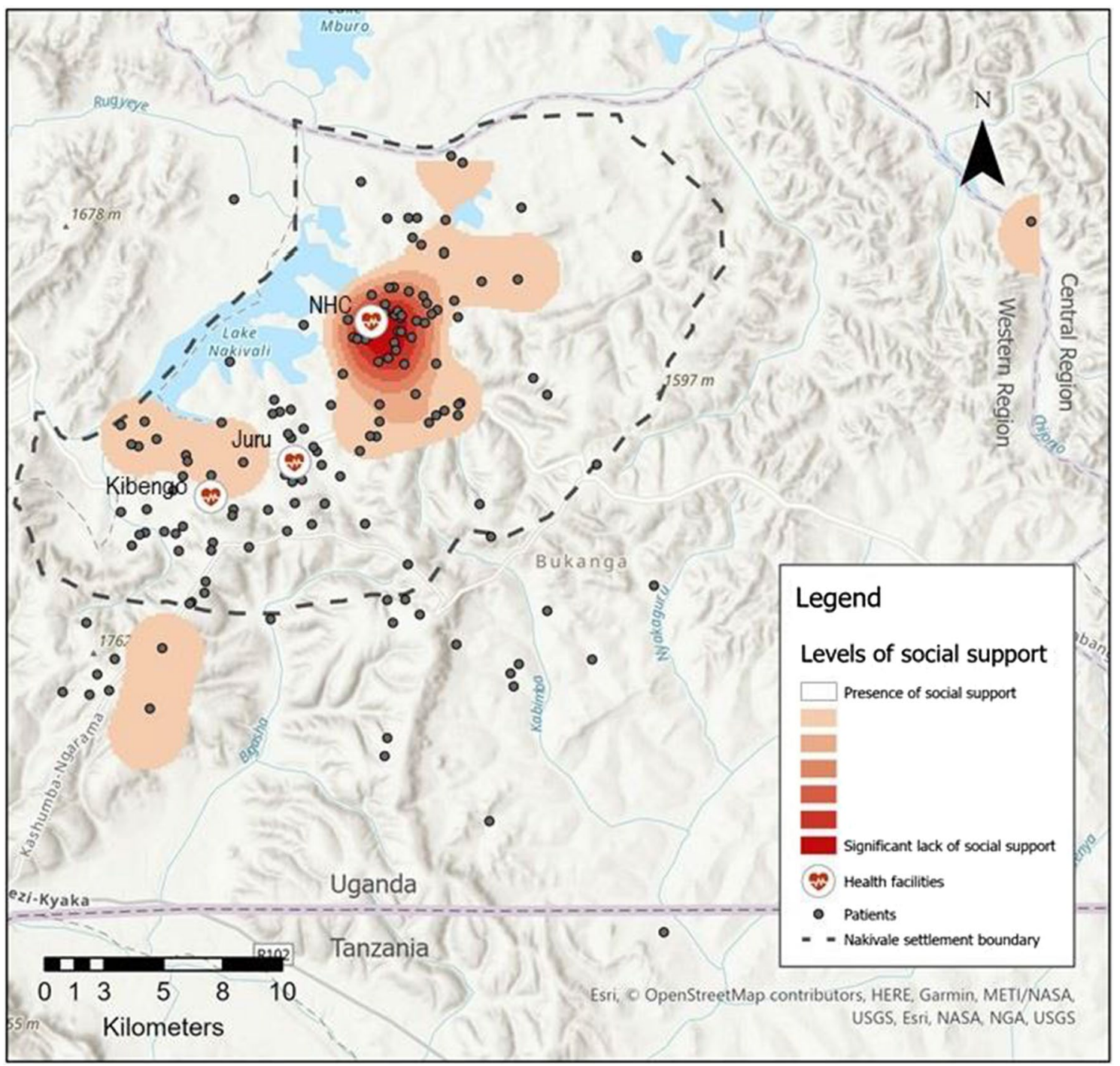

Fig. 1 Kernel density map of levels of social support for participants who tested positive for HIV juxtaposed with all participants who tested positive for HIV, health care facilities (including Nakivale

the exception of social support. Those with greater social support were more likely to link to care compared to those with lower social support. In our analyses exploring factors related to social support, we found that more years of schooling was significantly associated with increased social support. It is important to note that although the prevalence of mental health issues was relatively high in our study (approximately $43 \%$ of all participants screened positive for PTSD, 25\% for depression and 23\% for anxiety), these estimates are comparable or lower than that observed in other studies in similar and nearby regions. [28-31].

In the spatial analyses, we found that participants did not consistently link to HIV care at the closest health center to their primary residence and the distance traveled to clinic was highly variable both within and across sites. We
Health Center [NHC], Juru Clinic, and Kibengo Clinic), and the Nakivale settlement boundary

did not collect data about why a participant may not have linked to care at their nearest clinic. However, prior work in this region suggests some people decline to attend the clinic nearest to their home to decrease the possibility of involuntary HIV status disclosure to people in their community $[32,33]$. The Kernel density mapping illustrated that social support amongst HIV positive participants was lowest in Nakivale settlement and highest in the south of the study region. These findings may be reflective of differing proportions of Ugandan nationals in the study areas. Ugandan nationals likely had less disrupted social networks as they did not flee their country of origin like refugees, and may have more social support given longstanding social ties. Alternatively, the southern area of the study region is more rural, whereas Nakivale has the greatest population 
density. It may be that those living in more rural settings have stronger ties to their family and neighbors and benefit from that social support.

This study represents novel work in evaluating linkage to care barriers and facilitators for individuals residing in and around refugee settlements. Our finding regarding social support as a salient determinant of linkage to care suggests that interventions to bolster social support may be beneficial in increasing linkage to care and improving HIV outcomes more generally [34]. This is echoed in previous qualitative work in Nakivale, demonstrating that "Emotional support, particularly acceptance and encouragement, helped refugees overcome these fears [of an HIV diagnosis] to proceed with treatment. [35].

Interpretation of our findings is subject to certain limitations. First, the sample was non-random and not necessarily representative of the entire settlement community. For example, pregnant women more commonly access HIV testing from the maternity ward and therefore would have been less likely to enroll in this study. Second, the study population includes refugees and Ugandan nationals accessing HIV testing services in the refugee settlement. As such, the findings may not be generalizable to more homogenous refugee populations in Sub-Saharan Africa. Additionally, it is possible that some study participants that we classified as not linking to care could have linked to care at a clinic outside of the Nakivale catchment area, which would have biased our estimated linkage rates. Finally, only a subset (66\%) of the participants had GPS data available for the spatial analyses.

This research suggests that social support appears to increase linkage to care for individuals living in refugee settlements, and linkage to care in this study was more frequent than in previous studies in this settlement [12], suggesting that linkage has improved over time. However, this rate is below the national Ugandan reports of $88.4 \%$ of adults living with a known HIV status who report being in treatment [36], indicating that there is room for improvement in these refugee settlement communities. Linking HIV positive individuals to care can be challenging, and rates of care linkage are highly variable across regions in sub-Saharan Africa. The likelihood of timely linkage is often dependent on the modality of testing (facility- vs. community-based) with linkage estimates ranging from $26 \%$ to $95 \%$. [37] Identifying factors that promote or inhibit linkage to care is critical for the attainment of the UNAIDS fast track goal of having 95\% of those diagnosed with HIV to be engaged in care [10]. Interventions which strengthen existing support systems or establish new networks of support for individuals living with HIV may have the potential to improve progression along the HIV care continuum in refugee settlements and bolster national HIV programming to improve linkage in testing programs with sub-optimal linkage rates. [37].
Improving linkage to HIV care is the next important step after the expansion of HIV testing programs. This study demonstrated that social support is associated with timely linkage to care. Leveraging social support networks and resources may improve linkage to care for those newly diagnosed with HIV in refugee settlements in Uganda.

Acknowledgements The authors are grateful to the study participants who volunteered their time to contribute to this research to help improve healthcare for refugees and Ugandan nationals in Nakivale Refugee Settlement. We thank the research assistants Kamaganju Stella, Kampire Caroline, Iraguha Patient, Kambale Ntuyenabo, Uzamukunda Pascal Rubumba, Valentine Nshimiyimana, and Muhongayire Bernadette, whose diligent and compassionate work made this research possible. We appreciate the support offered by the medical staff at Nakivale, Juru, and Kibengo Health Centers and their dedication to the clients they serve. We thank the United Nations High Commissioner for Refugees in Uganda and the Office of the Prime Minister in Mbarara for their assistance and support throughout the study.

Author contributions KNO, IVB and ACT designed the study. ZF and SM collected and maintained the data. CP, JS and EN analyzed the data. CP drafted the manuscript. All authors contributed to editing and review. IB provided mentorship and contributed to manuscript drafts and interpretation of findings. All authors approved the final manuscript.

Funding This work was supported by the U.S. National Institutes of Health (NIH) (K23MH108440, K24AI141036) and the University of Washington/Fred Hutchinson Center for AIDS Research (NIH P30AI027757). The content is solely the responsibility of the authors and does not necessarily represent the official views of the NIH.

Data availability Not available due to stipulations in the ethics approval process.

Code availability Not applicable.

\section{Declarations}

Conflict of interest The authors have no disclosures or conflicts of interest.

Ethical approval This study was approved by the Makerere University School of Health Sciences Research and Ethics Committee, Kampala, Uganda (SHSREC REF No. 2012-020), the University of Washington Human Subjects Division, Seattle, Washington, USA (STUDY00007766), and the Mass General Brigham Institutional Review Board, Boston, Massachusetts, USA (2012P000839). Clearance to conduct this research was also obtained from the Ugandan National Council of Science and Technology (HS 1167).

Consent to participate Study participants provided written informed consent.

Consent for publication Not applicable.

Open Access This article is licensed under a Creative Commons Attribution 4.0 International License, which permits use, sharing, adaptation, distribution and reproduction in any medium or format, as long as you give appropriate credit to the original author(s) and the source, provide a link to the Creative Commons licence, and indicate if changes 
were made. The images or other third party material in this article are included in the article's Creative Commons licence, unless indicated otherwise in a credit line to the material. If material is not included in the article's Creative Commons licence and your intended use is not permitted by statutory regulation or exceeds the permitted use, you will need to obtain permission directly from the copyright holder. To view a copy of this licence, visit http://creativecommons.org/licenses/by/4.0/.

\section{References}

1. World Health Organization. HIV/AIDS. Published 2021. 2021. https://www.afro.who.int/health-topics/hivaids. Accessed 14 May.

2. Pew Research Center. Record number of forcibly displaced people lived in sub-Saharan Africa in 2017. Published 2018. https://www. pewresearch.org/fact-tank/2018/08/09/record-number-of-forciblydisplaced-people-lived-in-sub-saharan-africa-in-2017/. Accessed 22 April 2021

3. UNHCR. United Nations High Commissioner for Refugees. https://www.unhcr.org/en-us/africa.html. Accessed 21 April 2021

4. UNAIDS, UNHCR. Strategies to Support the HIV-Related Needs of Refugees and Host Populations; 2005. http://data.unaids.org/ publications/irc-pub06/jc1157-refugees_en.pdf. Accessed 5 May 2021

5. O'Laughlin KN, Rouhani SA, Faustin ZM, Ware NC. Testing experiences of HIV positive refugees in Nakivale Refugee Settlement in Uganda: Informing interventions to encourage priority shifting. Confl Health. 2013. https://doi.org/10.1186/ 1752-1505-7-2.

6. Tanaka Y, Kunii O, Hatano T, Wakai S. Knowledge, attitude, and practice (KAP) of HIV prevention and HIV infection risks among Congolese refugees in Tanzania. Health Place. 2008;14:434-52. https://doi.org/10.1016/j.healthplace.2007.07.005.

7. United Nations High Commissioner for Refugees (UNHCR). Operational Guidance Mental Health \& Psychosocial Support Programming for Refugee Operations. Published 2013. https:// www.unhcr.org/protection/health/525f94479/operational-guida nce-mental-health-psychosocial-support-programming-refugee. html. Accessed 5 May 2021

8. UNAIDS and UNHCR. POLICY BRIEF: HIV and Refugees; 2007. https://data.unaids.org/pub/briefingnote/2007/policy_brief_refug ees.pdf. Accessed 5 May 2021

9. O'Laughlin KN, Rouhani SA, Kasozi J, et al. A qualitative approach to understand antiretroviral therapy (ART) adherence for refugees living in Nakivale Refugee Settlement in Uganda. Confl Health. 2018. https://doi.org/10.1186/s13031-018-0145-1.

10. UNAIDS. Fast-Track Targets; 2020. https://www.unaids.org/sites/ default/files/media_asset/201506_JC2743_Understanding_FastT rack_en.pdf. Accessed 5 May 2021

11. Ravicz M, Muhongayire B, Kamagaju S, et al. Using Intervention Mapping methodology to design an HIV linkage intervention in a refugee settlement in rural Uganda. AIDS Care - Psychol SocioMedical Asp AIDS/HIV. Published online 2021. https://doi.org/ 10.1080/09540121.2021.1900532

12. O'Laughlin KN, Kasozi J, Rabideau DJ, et al. The cascade of HIV care among refugees and nationals in Nakivale Refugee Settlement in Uganda. HIV Med. 2017;18(7):513-8. https://doi.org/ 10.1111/hiv.12476.

13. Kranzer K, Govindasamy D, Ford N, Johnston V, Lawn SD. Quantifying and addressing losses along the continuum of care for people living with HIV infection in sub-Saharan Africa: Systematic review. J Int AIDS Soc. 2012;15(2):17383. https://doi.org/10. 7448/IAS.15.2.17383.

14. Government of Uganda Office of the Prime Minister. Government of uganda office of the prime minister uganda refugees \& asylum seekers as of 31-October-2019 Population summary by settlement /sex. Uganda refugees \& asylum seekers as of 31-October-2019 population summary by country of origin/ sex. Published 2021. https://data2.unhcr.org/en/documents/details/83566. Accessed 14 May 2021

15. O'Laughlin KN, Kasozi J, Walensky RP, et al. Clinic-based routine voluntary HIV testing in a refugee settlement in Uganda. J Acquir Immune Defic Syndr. 2014;67(4):409-13. https://doi.org/ 10.1097/QAI.0000000000000317.

16. Harris PA, Taylor R, Thielke R, Payne J, Gonzalez N, Conde JG. Research electronic data capture (REDCap)-a metadata-driven methodology and workflow process for providing translational research informatics support. J Biomed Inform. 2009;42(2):37781. https://doi.org/10.1016/J.JBI.2008.08.010.

17. Lang AJ, Stein MB. An abbreviated PTSD checklist for use as a screening instrument in primary care. Behav Res Ther. 2005;43(5):585-94. https://doi.org/10.1016/J.BRAT.2004.04.005.

18. Kroenke K, Spitzer RL, Williams JBW. The PHQ-9: Validity of a brief depression severity measure. J Gen Intern Med. 2001;16(9):606-13. https://doi.org/10.1046/j.1525-1497.2001. 016009606.x.

19. Manea L, Gilbody S, McMillan D. Optimal cut-off score for diagnosing depression with the Patient Health Questionnaire (PHQ9): A meta-analysis. CMAJ. 2012;184(3):E191. https://doi.org/ 10.1503/cmaj.110829.

20. Spitzer RL, Kroenke K, Williams JBW, Löwe B. A brief measure for assessing generalized anxiety disorder: The GAD-7. Arch Intern Med. 2006;166(10):1092-7. https://doi.org/10.1001/archi nte.166.10.1092.

21. Plummer F, Manea L, Trepel D, McMillan D. Screening for anxiety disorders with the GAD-7 and GAD-2: a systematic review and diagnostic metaanalysis. Gen Hosp Psychiatry. 2016;39:2431. https://doi.org/10.1016/j.genhosppsych.2015.11.005.

22. Mughal AY, Devadas J, Ardman E, et al. A systematic review of validated screening tools for anxiety disorders and PTSD in low to middle income countries. BMC Psychiatr. 2020. https://doi.org/ 10.1186/S12888-020-02753-3.

23. Nakku JEM, Rathod SD, Kizza D, et al. Validity and diagnostic accuracy of the Luganda version of the 9-item and 2-item Patient Health Questionnaire for detecting major depressive disorder in rural Uganda. Glob Ment Heal. 2016;3(20):1-8. https://doi.org/ 10.1017/GMH.2016.14.

24. Bjärtå A, Leiler A, Ekdahl J, Wasteson E. Assessing Severity of Psychological Distress Among Refugees With the Refugee Health Screener, 13-Item Version. J Nerv Ment Dis. 2018;206(11):834. https://doi.org/10.1097/NMD.0000000000000886.

25. Beutel ME, Brähler E, Wiltink J, et al. Emotional and tangible social support in a German population-based sample: development and validation of the Brief Social Support Scale (BS6). PLoS One. 2017;12(10): e0186516. https://doi.org/10.1371/journ al.pone. 0186516 .

26. Uganda Bureau of, Statistics. Uganda Demographic and Health Survey 2016. www.DHSprogram.com

27. Humanitarian Open Streen Map Team. Uganda Roads (OpenStreetMap Export) - Humanitarian Data Exchange. https://data. humdata.org/dataset/hotosm_uga_roads. Accessed 5 May 2021

28. Bapolisi AM, Song SJ, Kesande C, Rukundo GZ, Ashaba S. Posttraumatic stress disorder, psychiatric comorbidities and associated factors among refugees in Nakivale camp in southwestern Uganda. BMC Psychiatry. 2020;20(1):1-10. https://doi.org/10. 1186/S12888-020-2480-1/TABLES/5.

29. Logie CH, Berry I, Okumu M, et al. The prevalence and correlates of depression before and after the COVID-19 pandemic declaration among urban refugee adolescents and youth in informal settlements in Kampala, Uganda: A longitudinal cohort study. Ann 
Epidemiol. Published online November 14, 2021. https://doi.org/ 10.1016/J.ANNEPIDEM.2021.11.005

30. Kabunga A, Anyayo LG. Prevalence of Depressive Disorders and Associated Demographic Factors Among Refugees Amidst COVID-19 in Nakivale Refugee Camp in Southwestern Uganda. medRxiv. 2020. https://doi.org/10.1101/2020.10.21.20216754.

31. Bogic M, Njoku A, Priebe S. Long-term mental health of warrefugees: a systematic literature review. BMC Int Health Hum Rights. 2015;15(1):1-41. https://doi.org/10.1186/S12914-0150064-9/TABLES/3.

32. Camlin CS, Charlebois ED, Getahun M, et al. Pathways for reduction of HIV-related stigma: a model derived from longitudinal qualitative research in Kenya and Uganda. J Int AIDS Soc. 2020;23(12):e25647. https://doi.org/10.1002/JIA2.25647.

33. Naigino R, Makumbi F, Mukose A, et al. HIV status disclosure and associated outcomes among pregnant women enrolled in antiretroviral therapy in Uganda: a mixed methods study. Reprod Health. 2017;14(1):1-11. https://doi.org/10.1186/S12978-0170367-5/TABLES/6.

34. Katz IT, Ryu AE, Onuegbu AG, et al. Impact of HIV-related stigma on treatment adherence: systematic review and meta-synthesis. J Int AIDS Soc. 2013. https://doi.org/10.7448/ ias.16.3.18640.

35. Rouhani SA, O'Laughlin KN, Faustin ZM, Tsai AC, Kasozi J, Ware NC. The role of social support on HIV testing and treatment adherence: a qualitative study of HIV-infected refugees in southwestern Uganda. Glob Public Health. 2017;12(8):1051-64. https://doi.org/10.1080/17441692.2015.1132472.

36. WHO/Ministry of Health. Uganda Population-Based Hiv Impact Assessment UPHIA 2016-2017; 2017. https://afro.who.int/sites/ default/files/2017-08/UPHIAUgandafactsheet.pdf. Accessed 5 May 2021

37. Sharma M, Ying R, Tarr G, Barnabas R. Systematic review and meta-analysis of community and facility-based HIV testing to address linkage to care gaps in sub-Saharan Africa. Nat. 2015. https://doi.org/10.1038/nature16044.

Publisher's Note Springer Nature remains neutral with regard to jurisdictional claims in published maps and institutional affiliations. 